$\begin{array}{ccccc}\begin{array}{c}\text { Laboratory } \\ \text { number }\end{array} & \begin{array}{c}\text { Published } \\ \text { reference } \begin{array}{c}\text { Original date or } \\ \text { other value }\end{array}\end{array} & \begin{array}{c}\text { Corrected date } \\ \text { or other value }\end{array} & \partial \mathrm{C}^{14}, \% 0 \\ -263 & 152: 37 & 27,670 \pm 410 & & \\ -268 & 152: 27, & & \\ & 42 & >36,000 & \mathrm{~d} \\ -268 & 152: 42 & >41,200 & \\ -269 & 152: 39 & 9400 \pm 150 & \\ -272 & 152: 27, & & \\ & 30 & 6920 \pm 140 & \\ -280 & 152: 31 & 6320 \pm 140 & \end{array}$

A.D./

B.C. date

25,720 B.C.

7450 B.C.

4970 B.C.

4370 B.C.

${ }^{1}$ L-455B.

${ }^{2}$ Gro-2597, 2601.

${ }^{3} \mathrm{~L}-221 \mathrm{C}$.

\title{
Geochron Laboratories, Inc.
}

\begin{tabular}{|c|c|c|c|c|c|}
\hline $\begin{array}{l}\text { Laboratory } \\
\text { number }\end{array}$ & $\begin{array}{l}\text { Published } \\
\text { reference }\end{array}$ & $\begin{array}{l}\text { Original date or } \\
\text { other value }\end{array}$ & $\begin{array}{l}\text { Corrected date } \\
\text { or other value }\end{array}$ & $\partial \mathrm{C}^{14}, \%$ & $\begin{array}{l}\text { A.D./ } \\
\text { B.C. date }\end{array}$ \\
\hline GX-87 & $153: 52$ & $4730 \pm 310$ & & & 2780 B.C. \\
\hline-88 & $153: 52$ & $6754 \pm 290$ & & & 4804 B.C. \\
\hline-89 & $153: 52$ & $7045 \pm 175$ & & & 5095 B.C. \\
\hline$-93^{1}$ & $153: 48$ & $4575 \pm 320$ & & & 2625 B.C. \\
\hline-94 & $153: 52$ & $1200 \pm 125$ & & & A.D. 750 \\
\hline-95 & $153: 52$ & $1225 \pm 140$ & & & A.D. 725 \\
\hline-103 & $153: 53$ & $1545 \pm 75$ & & & A.D. 405 \\
\hline .104 & $153: 53$ & $6255 \pm 135$ & & & 4305 B.C. \\
\hline-105 & $153: 48$ & $14,000 \pm 225$ & & & 12,050 B.C. \\
\hline-107 & $153: 49$ & $1270 \pm 100$ & & & A.D. 680 \\
\hline-108 & $153: 53$ & $1860 \pm 180$ & & & A.D. 90 \\
\hline-109 & $153: 52$ & $750 \pm 135$ & & & A.D. 1200 \\
\hline-137 & $153: 49$ & $190 \pm 100$ & & & A.D. 1760 \\
\hline-138 & $153: 49$ & $625 \pm 80$ & & & A.D. 1325 \\
\hline-145 & $153: 48$ & $13,170 \pm 600$ & & & 11.220 B.C \\
\hline-146 & $153: 49$ & $2650 \pm 130$ & & & 700 B.C. \\
\hline-147 & $153: 49$ & $945 \pm 120$ & & & A.D. 1005 \\
\hline-155 & $153: 48$ & $2575 \pm 80$ & & & 625 B.C. \\
\hline-162 & $153: 49$ & $2195 \pm 164$ & & & 245 B.C. \\
\hline-163 & $153: 50$ & $2830 \pm 130$ & & & 880 B.C. \\
\hline-164 & $153: 50$ & $2245 \pm 125$ & & & 295 B.C. \\
\hline-165 & $153: 50$ & $2450 \pm 120$ & & & 500 B.C. \\
\hline-166 & $153: 50$ & $1690 \pm 155$ & & & A.D. 260 \\
\hline-167 & $153: 50$ & $2030 \pm 120$ & & & 80 B.C. \\
\hline-168 & $153: 50$ & $1845 \pm 110$ & & & A.D. 105 \\
\hline-169 & $153: 50$ & $1990 \pm 130$ & & & 40 B.C. \\
\hline-170 & $153: 50$ & $1275 \pm 115$ & & & A.D. 675 \\
\hline-171 & $153: 51$ & $1965 \pm 225$ & & & 15 B.C. \\
\hline-172 & $153: 51$ & $2695 \pm 185$ & & & 745 B.C. \\
\hline-185 & $153: 51$ & $3890 \pm 90$ & & & 1940 B.C. \\
\hline-186 & $153: 51$ & $3820 \pm 85$ & & & 1870 B.C. \\
\hline-187 & $153: 51$ & $3745 \pm 165$ & & & 1795 B.C. \\
\hline-193 & $153: 48$ & GX-93 & & & \\
\hline-194 & $153: 48$ & $4620 \pm 130$ & & & 2670 B.C. \\
\hline-208 & $153: 51$ & $2725 \pm 80$ & & & 775 B.C. \\
\hline
\end{tabular}

${ }^{1}$ Pub. in error as GX-193 